\title{
LARGE-STRAIN QUASI-STATIC COMPRESSION MATERIALS TESTS IN SUPPORT OF PENETRATION MODELING RESEARCH
}

\author{
S. L. Brandon and J. J. Totten \\ Sandia National Laboratories \\ Livermore, California 94551
}

\begin{abstract}
Target penetration by projectiles typically generates large strains, at least locally. Hence, accurate analytic modeling of penetration demands that constitutive models be calibrated using large strain materiail test data.

Tensile test dat; $s$ limited by specimen necking (the Considere criterion), restricting attainable strains. Linear extrapolation of tensile data to larger strains can seriously overestimate the material flow stress, resulting in erroneously stiff analytical predictions. That is, other tests which can attain larger strains often reveal a continually decreasing tangent modulus at large strains.

We report quasistatic room temperature compression tests approaching true strains of $\varepsilon=-1$. A few tensile tests are included to illustrate the previous point. Materials tested are 7075-T651, 5083-H131, and 6061-T651 aluminum alloys, 4340 steel, and X21-C Tungsten alloy.
\end{abstract}




\section{ACKNOWLEDGEMENTS}

Technical support from J. S. Korellis, K. L. Lee, C. A. Steinhaus, M. L. Tootle, and D. R. Williams of Sandia National Laboratories is gratefully acknowledged.

Continuing consultation with Professor A. K. Mukherjee, University of California, Davis, is deeply appreciated. This research was supported in part by Vincent Luk of Sandia's 9123 Advanced Projects Division III.

The authors thank Martha Campiotti, 8244 , for her skillful assistance in preparing this report. 


\section{CONTENTS}

Experimental Technique

Materials Test Results

7075-T651 Aluminum

5083-H131 Aluminum

6061-T651 Aluminum

4340 Steel

X21-C 93\% Tungsten Ailoy

Conclusions

References

20 


\section{EXPERIMENTAL TECHNIQUE}

Compression tests were performed at constant true strain rate using a computercontrolled MTS 880 materials test frame. To enhance system stiffness, the $20 \mathrm{kip}$ (20,000 pound-force) actuator is mounted in a 50 kip test frame. Actuator alignment is maintained by a hydrostatic bearing. The test frame crosshead is strain gaged to provide load data, eliminating the need for a separate load cell with its associated compliance and alignment disadvantages.

Compression specimens are nominally 0.320 " tall by 0.200 " in diameter with ends lightly grooved to entrap Molybdenum Disulfide lubricant. The specimen is compressed between two parallel tungsten carbide platens lapped to a mirror finish. These techniques result from a separate experimental parametric study on the influence of specimen design on stress-strain data, Reference 1 . A general discussion of compression and other materials test techniques is available in Reference 2.

Tensile specimens had a nominal diameter of $0.125^{n}$ over a $1.5^{\prime \prime}$ long uniform section. Specimen ends were threaded into (1-joints to minimize any bending stresses; a strain-gaged load cell and a $0.500 "$ long extensometer provided the raw data for calculation of stress and strain.

To calculate true stres all materials were assumed incompressible; this is a reasonable approximation for metals undergoing large strains as in our situation. 


\section{MATERIALS TEST RESULTS}

\section{5-T651 ALUMINUM}

The material provided was the smaller portion of a solid rod which had been axially sliced parallel to but not intersecting its centerline. That is, no material from the rod center was provided for extracting specimens.

Compression specimens oriented both axially and radially behaved anisotropically, as compression deformation was accompanied by skewing from the onset. This anisotropy may be caused by some texture developed during thermo-mechanical processing of the rod.

Axially oriented tensile specimens exhibited yield and ultimate (True) stresses of 70 and 86 ksi respectively, with a uniform elongation of about 11-12 percent. These are close to handbook values.

Following the hypothesis that the anisotropy might be axisymmetric, subsequent axial compression specimens provided us (ostensibly extracted from the center of a similar rod) did not exhibit the previous gross skewing. They failed by shear on 45-degree planes at a true strain of about $\varepsilon=-0.80$.

Typical tensile and compression data are plotted; the nominal strain rate is 0.01 to 0.10 per second. This material and many other aluminum alloys except for highest purity aluminum are known to be strain-rate insensitive to at least $100 / \mathrm{sec}$. 


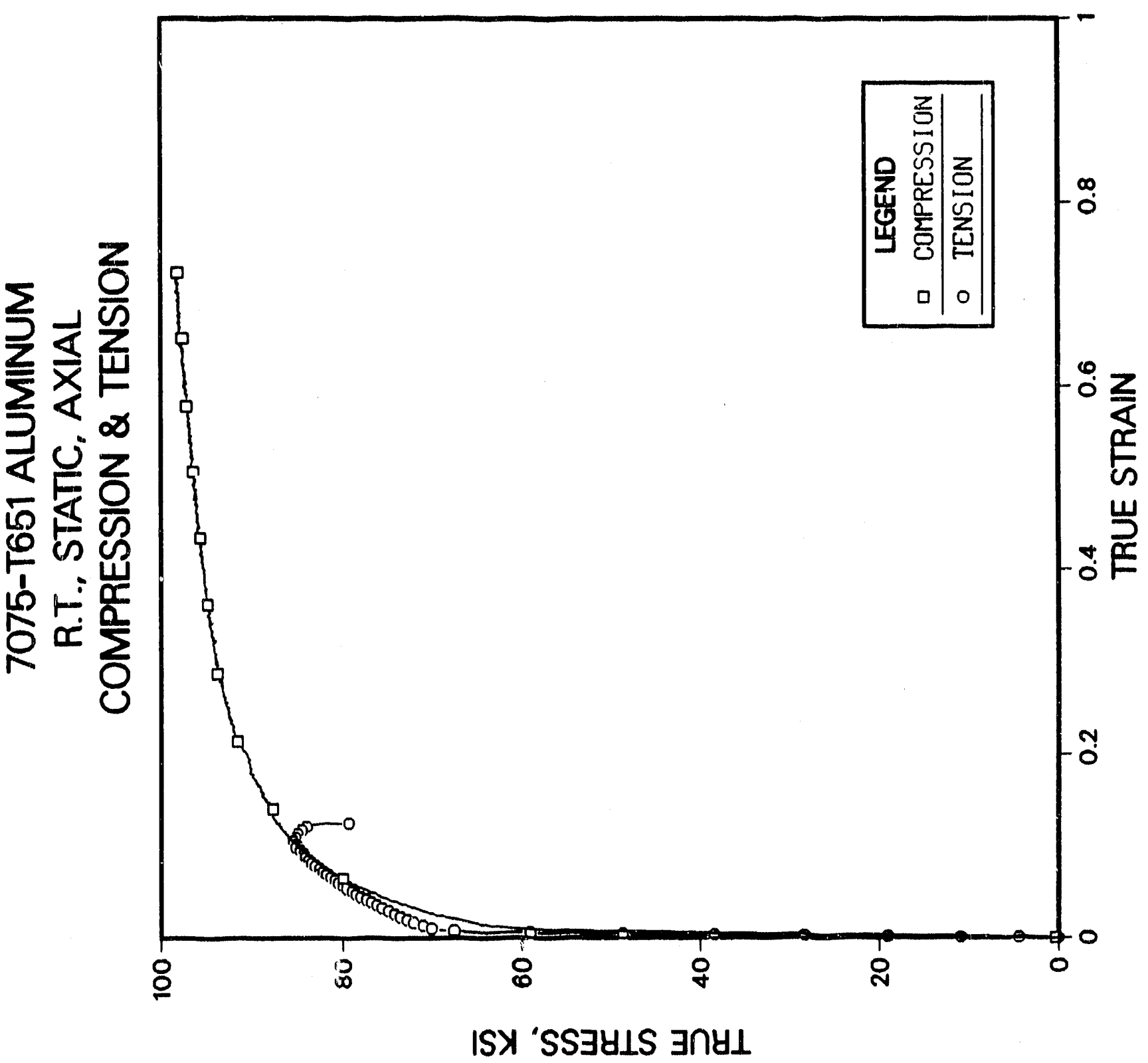




\section{3-H131 ALUMINUM}

Two 1 " $\times 12^{n}$ strips of material were provided-one about $1 / 2$-inch thick and the other about 2-inch thick. To document anisotropic behavior, the long dimension of each strip was called the "Longitudinal" direction. Longitudinal, transverse, and throughthickness compression specimens at 1.0 per second were tested. Some stress-strain curves (especially for the Through-Thickness direction) appeared erratic, as if deformation were progressing nonhomogeneously.

Generally, the longitudinal stress-strain curve lies below those of the other directions for strains up to about $\varepsilon=-0.3$, but all curves tend to coalesce as the strain approaches about $\varepsilon=-1.0$. The 2 -inch thick plate has only slightly higher corresponding flow stresses than the 1/2-inch thick plate. 


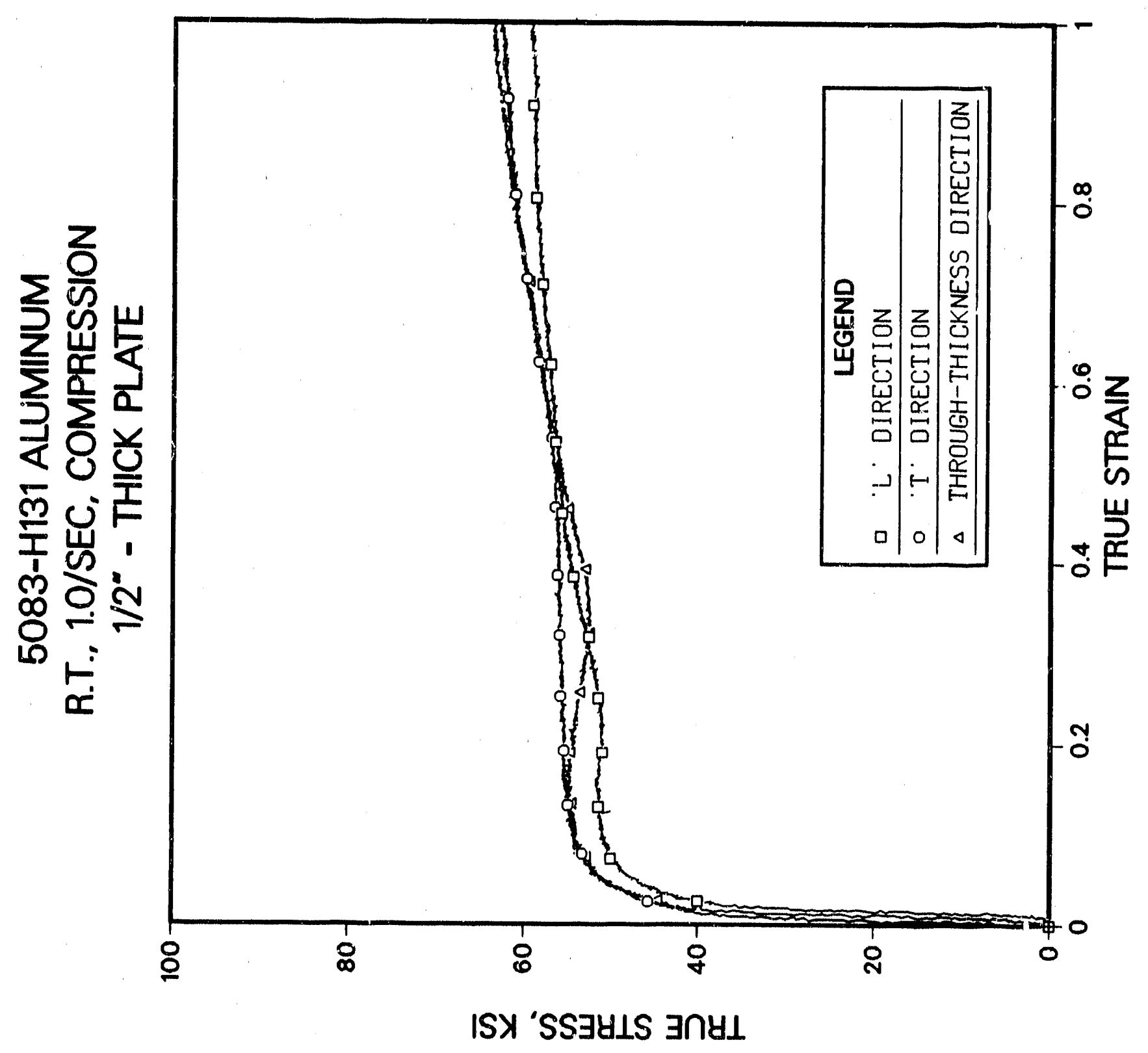




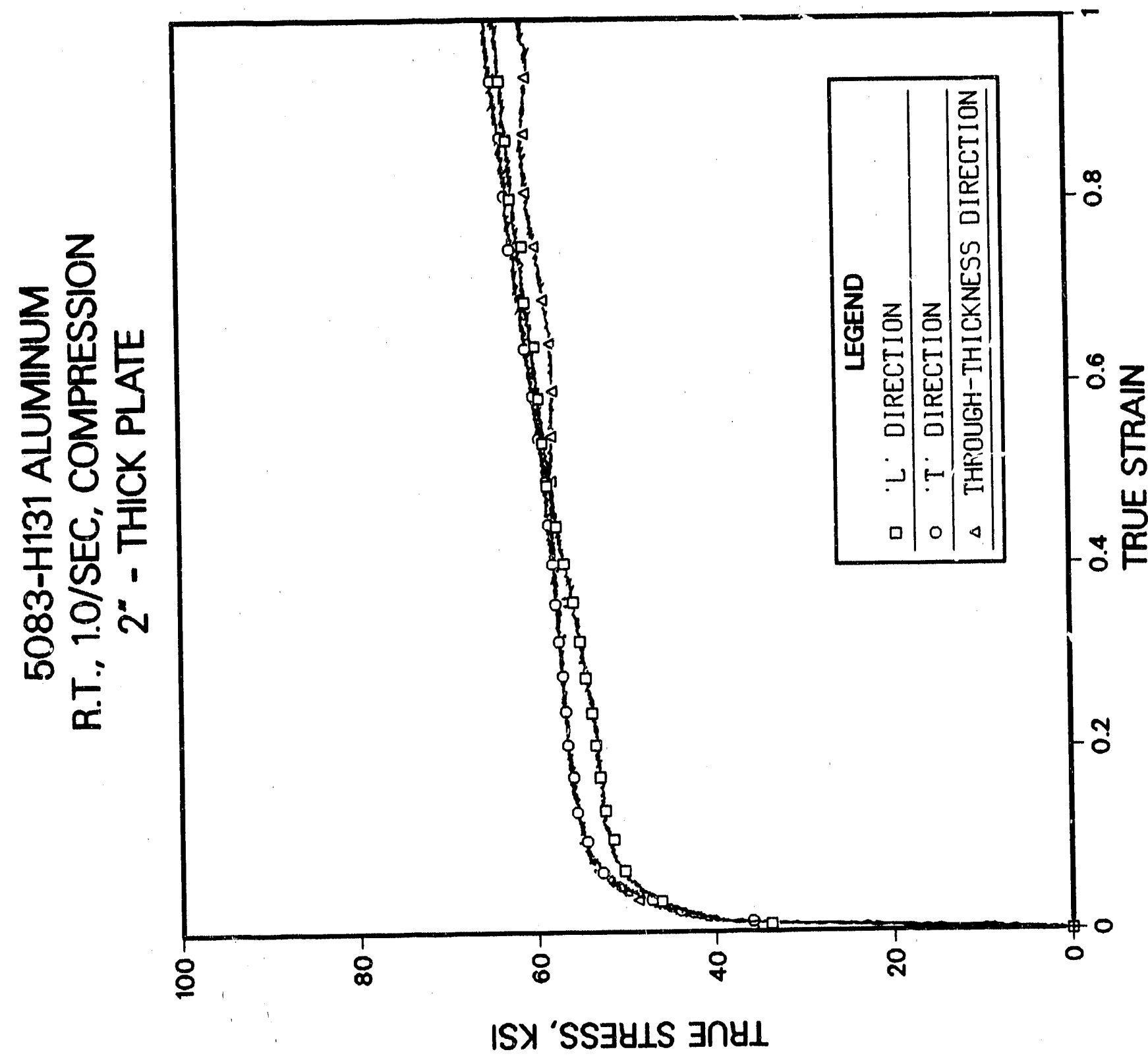




\section{1-T651 ALUMINUM}

Compression specimens extracted in axial and radial directions at random positions from a 6 -inch diameter by 1.5 -inch thick disk exhibited significant skewing deformation from the onset of yield. Hence, the most we could infer from these tests is the yield stress; these were approximately $42 \mathrm{ksi}$ and $38 \mathrm{ksi}$ for the axial and radial directions, respectively. (The standard specimen size was then increased 50 percent with similar results.) These indicate that the material had a significant anisotropy, perhaps by texture development during its processing.

Subsequent axial compression specimens provided to us, purportedly from the center section of another disk, were also tested. Yield stresses exceeded those of the previous batch of material, centering about $52 \mathrm{ksi}$ ( 30 percent above textbook value). Skewing again accompanied compression (characterized by post-yield inflections in the stress-strain curve), varying between specimens but generally less severe than that of the previous batch. Data from two tests with the least skewing are shown.

Supplementary compression tests on 3/4", 3", and 6" diameter typical SNL,L rod stock showed reasonably isotropic behavior without shearing deformation or inflections. An exarnple of these tests is shown. 


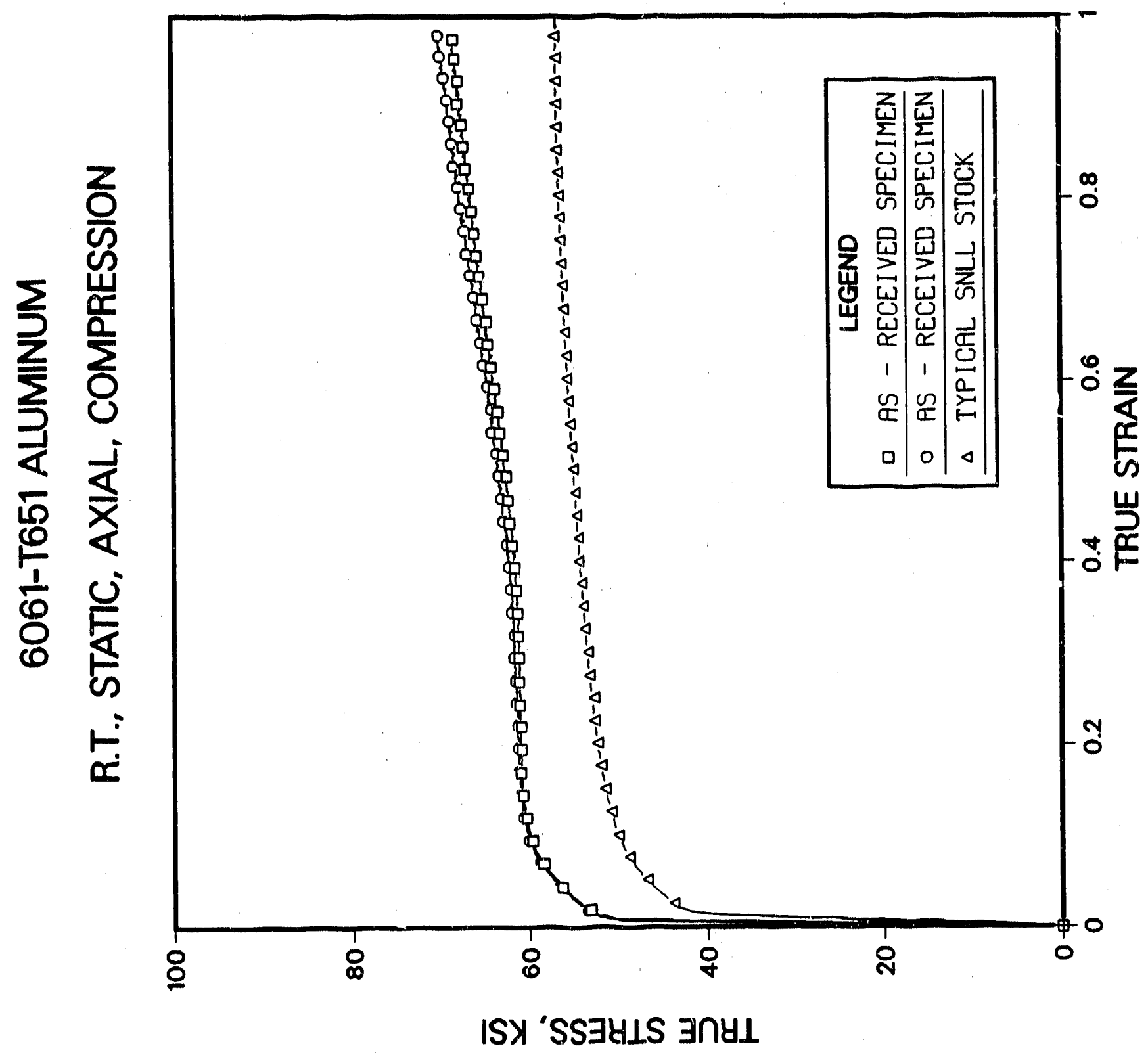




\section{STEEL}

We were provided a solid cylindrical slice, about 8-inch in diameter and 6-inch tall. This material is a good example of how extrapolating tensile stress-strain data to strains beyond necking can be in serious error.

In compression, axial and radial specimens were tested at rates of 0.0001 per second and 0.1 per second (any strain-rate sensitivity was negligible compared to specimento-specimen scatter). The flow stress is higher for the axial orientation than for the radial.

In tension, this axial/radial difference persists; tensile yield stresses were close to their compressive counterparts; cup-and-cone fracture was displayed. Necking occurs at such a small strain (about 5 percent) that linear extrapolation of the tensile plastic modulus to larger strains would be overly stiff, potentially resulting in unrealistic analytical structural response predictions. 


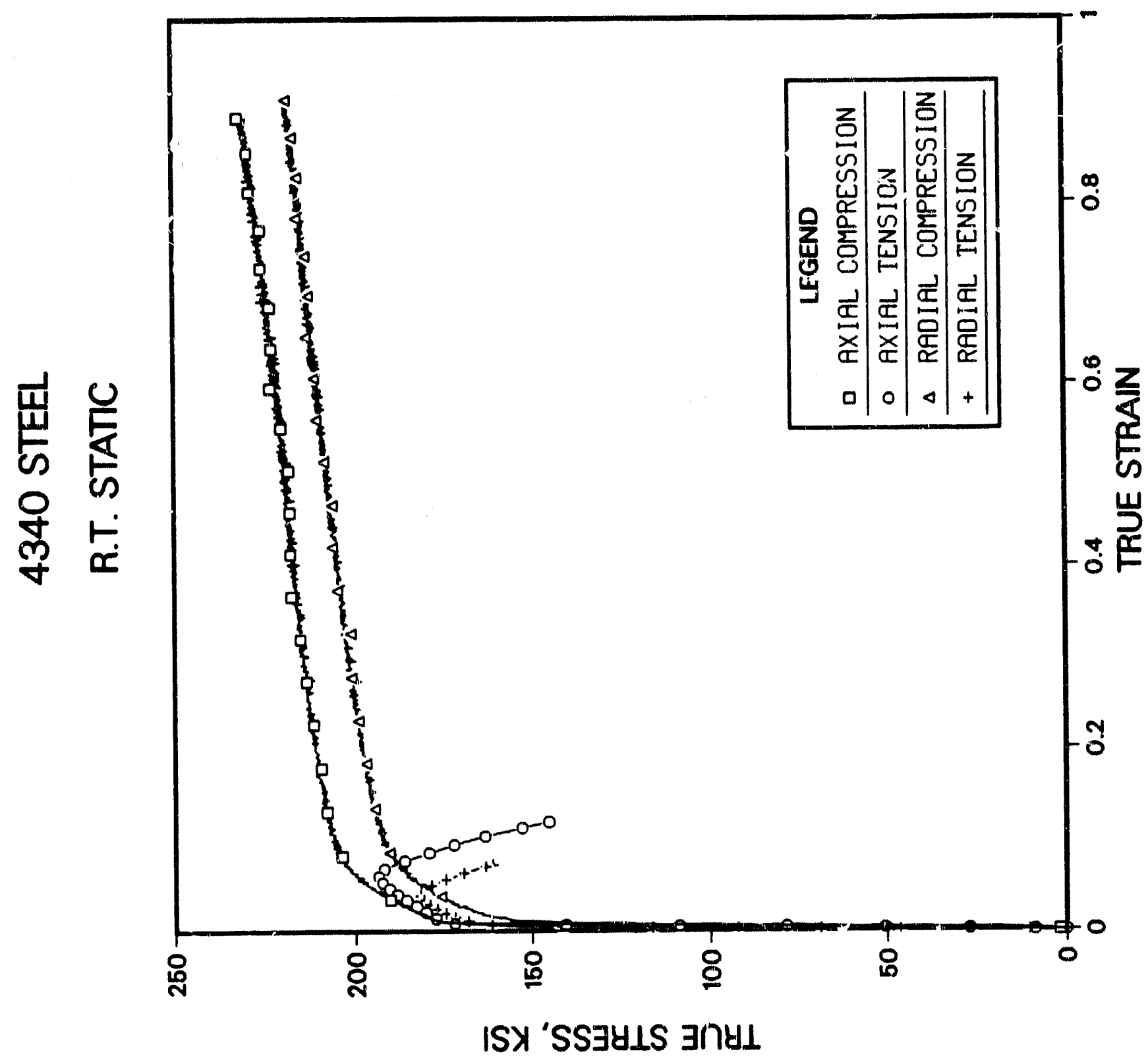




\section{X21-C 93\% TUNGSTEN ALLOY}

Axial compression specimens were machined from 0.2 -inch diameter roo stock. Tests at strain rates of 0.0001 per second and 0.1 per second revealed a signific' nt strai."rate sunsitivity; this is confirmed by a strain-rate jump test on a single specimen, where the strain rate was increased from 0.0001 per second to 0.1 per second at a strain of $\varepsilon=-0.27$, all in one continuous stroke.

The high strength of this material exceeded our force capacity at strains approe? hing $\varepsilon=-0.80$, and tesis are planned to achieve larger strains by remachining then recompressirig previously tested specimens. 


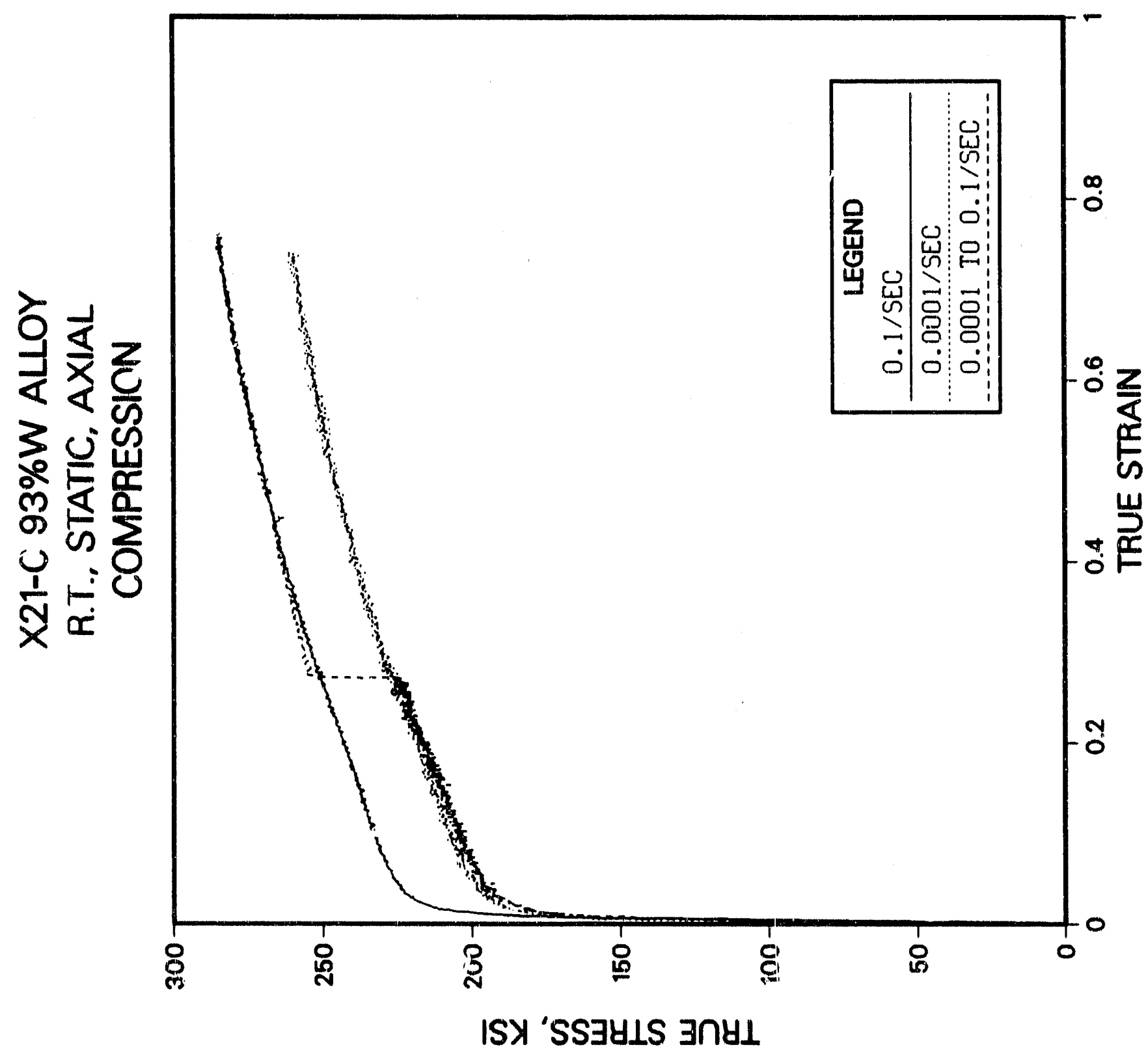




\section{CONCLUSIONS}

We have presented large-strain compressive stress-strain data for calibrating constitutive models for penetration analyses (for example, References 4-7). Materials tested were 7075-T651, 5083-H131, and 6061-T651 aluminum alloys, $4340 \mathrm{ste \theta l}$, and $\mathrm{X} 21-\mathrm{C}$ tungsten alloy.

The 7075-T651 and 6061-T651 alloy data must be interpreted cautiously because compression was accompanied by shear deformation: we presume this anisotropy results from material texture generated in processing. Better test data and corresponding analytical penetration predictions would result from more isotropic material stock.

For the range of static strain rates employed, no strain-rate sensitivity was anticipated or revealed by the aluminum alloys. The $\mathbf{4 3 4 0}$ steel also appears rate insensitive over the rates of $0.000 \mathrm{i} / \mathrm{sec}$ to $0.1 / \mathrm{sec}$ (literature data, Reference 3 , suggests that rate sensitivity for similar alloys may increase in the $10 / \mathrm{sec}$ strain rate regime). The X21-C tungsten alloy is highly rate-sensitive and is expected to continue to be so at higher rates.

To achieve larger strains, we are planning to remachine tested specimens followed by a second compression. Testing at higher strain rates is also planned and test equipment modifications are under way for elevated temperature testing.

Finally, we have illustrated that extrapolation of tensile stress-strain data to larger strains can be overly stiff. If large strains are anticipated in an analysis, the constitutive model should be calibrated to large strain material test data. 


\section{REFERENCES}

1. W. A. Kawahara, "Effects of Specimen Design in Large-Strain Compression," Experimental Techniques, March/April 1990, p.58.

2. Monograph on Structural Testing (in preparation), Society for Experimental Mechanics, R. 'T. Reese and W. A. Kawahara, Editors.

3. U. S. Lindholm and R. L. Bessey, "A Survey of Rate Dependent Strength Properties of Metals," Air Force Materials Laboratory, Ohio, Technical Report AFML-TR-69-119, April 1969.

4. V. Luk, M. J. Forrestal, and D. E. Amos, "Dynamic Spherical Cavity Expansion of Strain-Hardening Materials," to appear in Journal of Applied Mechanics.

5. M. J. Forrestal, N. S. Brar, and V. K. Luk, "Penetration of Strain-Hardening Targets With Rigid Spherical-Nose Rods," to appear in Journcl of Applied Mechanics.

6. V. K. Luk and D. E. Amos, "Dynamic Cylindrical Cavity-Expansion of Compressible Strain-Hardening Materials," to appear in Journal of Applied Mechanics.

7. M. J. Forrestal, V. K. Luk, and N. S. Brar, "Perforation of Aluminum Armor Plates With Conical-Nose Projectiles," to appear in Mechanics of Materials. 


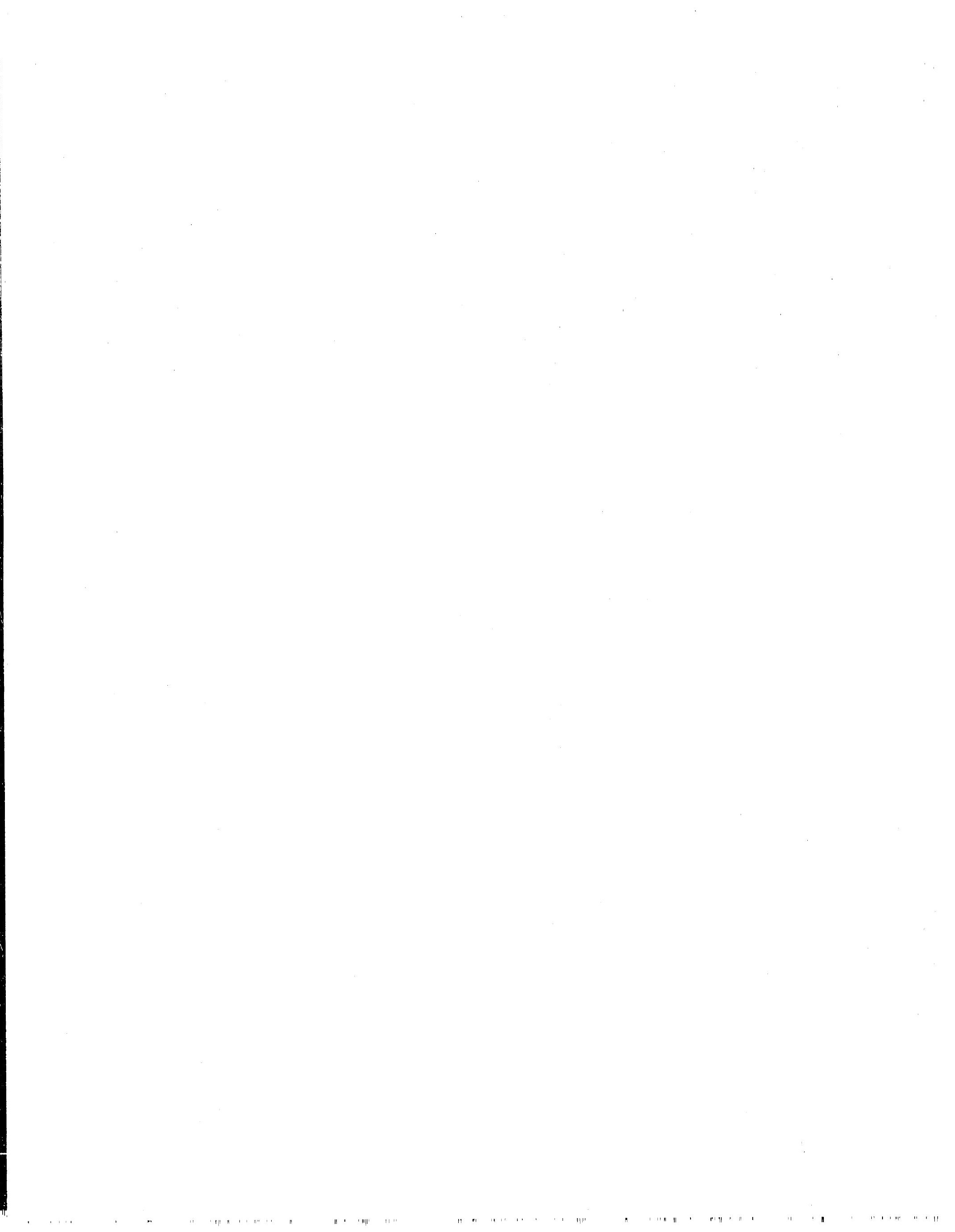

